\title{
EFEKTIVITAS BUAH KURMA DAN BUAH BIT TERHADAP KADAR HEMOGLOBIN PADA IBU HAMIL TRIMESTER II DI WILAYAH PUSKESMAS KARANGAWEN II KABUPATEN DEMAK
}

\author{
Wening Eka Cahya ${ }^{1}$, Ardhita Listya Fitriani ${ }^{2}$, Fhandy Aldy Mandaty ${ }^{3}$, Rizqitha ${ }^{4}$
} 1,2,3,4 STIKES Karya Husada Semarang

Email: ardhitalistyafitriani@gmail.com

\begin{abstract}
ABSTRAK
Ibu hamil yang menderita anemia berisiko mengalami keguguran, kelahiran prematur, bayi berat lahir rendah, dan perdarahan sebelum dan sesudah melahirkan. Data Puskesmas Karangawen II Kabupaten Demak jumlah ibu hamil tahun 2017 sebanyak 910 ibu hamil yang mengalami anemia. Pada tahun 2018 jumlah ibu hamil dengan anemia sebanyak 915, pada tahun 2019 terdapat 932 ibu hamil yang mengalami anemia. Tujuan penelitian adalah untuk mengetahui efektivitas buah kurma dan bit terhadap kadar hemoglobin pada ibu hamil trimester II di Puskesmas Karangawen II Kabupaten Demak. Jenis penelitian ini adalah eksperimen semu. Desain penelitian yang digunakan adalah two group pre-test-post-test design. Populasi penelitian adalah populasi ibu hamil trimester II di Puskesmas Karangawen II Kabupaten Demak yang mengalami anemia sebanyak 40 ibu hamil. Jumlah sampel ibu hamil trimester II di Puskesmas Karangawen II Demak sebanyak 38 orang. Sampel dibagi menjadi dua kelompok. 18 orang kelompok buah bit dan 18 orang kurma. Teknik pengambilan sampel dalam penelitian ini adalah purposive sampling. Hasil: Terdapat perbedaan kadar hemoglobin ibu hamil trimester II di Puskesmas Karangawen II Kabupaten Demak sebelum dan sesudah diberikan kurma. Terdapat perbedaan kadar hemoglobin ibu hamil trimester II di wilayah Puskesmas Karangawen II Kabupaten Demak sebelum dan sesudah diberikan buah bit.
\end{abstract}

Kata kunci: Kurma, Bit, Kadar Hemoglobin. 


\title{
EFFECTIVENESS OF KURMA AND BIT FRUIT ON HEMOGLOBIN LEVELS IN THE PREGNANT WOMEN MOTHER OF 2nd TRIMESTER AT PUSKESMAS KARANGAWEN II DEMAK AREA
}

\begin{abstract}
Pregnant women who suffer from anemia are at risk for miscarriage, premature birth, low birth weight babies, and bleeding before and after childbirth. Data from the Karangawen II Health Center, Demak Regency, the number of pregnant women in 2017 was 910 pregnant women who experienced anemia. In 2018 the number of pregnant women with anemia was 915, in 2019 there were 932 pregnant women with anemia. The purpose of this study was to determine the effectiveness of dates and beets on hemoglobin levels in pregnant women in the second trimester at Karangawen II Public Health Center, Demak Regency. This type of research is a quasi-experimental. The research design used was a two group pre-test-post-test design. The study population was the population of pregnant women in the second trimester at the Karangawen II Public Health Center, Demak Regency who experienced anemia as many as 40 pregnant women. The number of samples of pregnant women in the second trimester at the Karangawen II Health Center Demak was 38 people. The sample was divided into two groups. 18 people of beetroot group and 18 people of dates. The sampling technique in this research is purposive sampling. Results: There are differences in hemoglobin levels of pregnant women in the second trimester at Karangawen II Health Center, Demak Regency before and after being given dates. There are differences in hemoglobin levels of pregnant women in the second trimester in the Karangawen II Public Health Center, Demak Regency before and after being given beets.
\end{abstract}

Keywords: Date palms, Beets, Hemoglobin Levels

\section{PENDAHULUAN}

Anemia termasuk salah satu keadaan risiko tinggi dalam kehamilan yang dikarenakan gangguan pada medula spinalis dalam pembentukan eritrosit, sehingga mengakibatkan perdarahan. Ibu hamil anaemia memiliki haemoglobin yang rendah berkisar 
antara $7-10,5$ gr \%. Sehingga hanya ada sedikit darah merah yang beredar untuk mentransfer oksigen di dalam tubuh (Pratami, 2016).

WHO (2015) menyebutkan bahwa 800 ibu meninggal karena mengalami komplikasi pada saat kehamilan dan persalinan. Penyebab utama kematian pada ibu diantaranya yakni perdarahan, infeksi, hipertensi dan juga penyebab tidak langsung. Risiko ibu meninggal di negara berkembang 23 kali lebih tinggi dibandingkan dengan ibu di negara maju. Perdarahan yang terjadi pada saat proses kelahiran yang menyebabkan terjadinya anemia, dimana masalah ini seharusnya dapat dicegah (WHO, 2015). Masalah ibu dengan anemia di negara Indonesia prevalensinya lebih dari $50 \%$, sehingga menjadi utama dalam masalah kesehatan masyarakat. (Profil Kesehatan Indonesia, 2018).

Riskesdas (2018) menunjukkan bahwa data ibu hamil dengan anemia mencapai $48,9 \%$. Terjadi peningkatan dari data Riskesdas tahun 2013 yang menunjukkan presentase $37 \%$. Usia 15 24 tahun sebesar $84,6 \%$ menempati urutan pertama dalam kejadian ibu hamil dengan anemia, disusul usia 2534 tahun sebesar $33,7 \%$, usia 35-44 tahun sebesar 33,6\%, dan usia 45-54 tahun sebesar $24 \%$.

AKI Jawa Tengah tahun 2018 yaitu sebanyak 421 kasus atau 78,60 per 100.000 kelahiran hidup. Beberapa faktor penyebab kematian ibu diantaranya anemia yang bisa menyebabkan hipertensi (27,08\%), pendarahan(21,26\%), infeksi $(4,82 \%)$, gangguan sistem kardiovaskuler $(13,29 \%)$, dan lain-lain $(33,22 \%)$. Data profil Dinas Kesehatan Kabupaten (2018) bahwa ibu hamil dengan anemia sejumlah 19,58 \%. Tingginya kasus anemia pada ibu hamil menjadi masalah yang segera ditangani.

Cara mengatasi anemia pada ibu hamil yang sesuai dengan anjuran pemerintah biasanya melalui 2 cara yaitu farmakologi dan nonfarmakologi. Konsumsi tablet $\mathrm{Fe}$ (60mg) dan asamfolat (50 nanogram) selama kehamilan merupakan terapi farmakologi nya, sedangkan terapi nonfarmakologi berupa memakan sayur hijau, konsumsi buah kurma dan buah bit. (Pratami, 2016)

Buah kurma memiliki berbagai manfaat, salah satunya yaitu sebagai sumber zat besi (Fe) yang berperan sebagai komponen hemoglobin $(\mathrm{Hb})$. Hasil penelitian Rahayu (2017) menyebutkan sari kurma efektif dalam 
pemenuhan ibu hamil anemia, kurma mempunyai potensi meningkatkan kadar hemoglobin, sehingga dapat digunakan sebagai terapi alternatif atau pendukung pada ibu dengan anemia. Kandungan Fe pada kurma yaitu 1,02 mg sehingga mampu untuk membantu, mengobati maupun mencegah terjadinya anemia. Zat lain yang ada di dalam kurma yaitu Riboflavin, Piridoksal, Niasin, dan Folat, dimana 100 gram kurma dapat memenuhi lebih dari 9\% kebutuhan vitamin tubuh untuk sehari (Rahmawati, 2019).

Buah bit memiliki peran dalam pembersihan/penetralan racun dalam tubuh, dan penyembuhan infeksi maupun radang. ${ }^{(9)}$ Hasil penelitian Stephana (2018) menyebutkan bahwa pemberian bit efektif meningkatkan kadar $\mathrm{Hb}$ pada ibu hamil dengan anemia. Selain itu, kandungan $\mathrm{Fe}$ dan asam folat yang tinggi dalam buah bit berperan dalam pembentukan otak bayi. (Stephana, 2018)

Data di Puskesmas Karangawen II Kabupaten Demak jumlah ibu hamil tahun 2017 sebanyak 910 ibu hamil yang mengalami anemia berat sebanyak 18, sedang 145 dan ringan 182 . Tahun 2018 jumlah ibu hamil dengan anemia sebanyak 915, yang mengalami anemia berat sebanyak 22, sedang 152 dan ringan 194. Tahun 2019 ibu hamil dengan anemi sebanyak 932, yang mengalami anemia berat sebesar 26, sedang 161 dan ringan 190. Hasil wawancara dengan bidan koordinator penanganan anemia di Puskesmas Karangawen II adalah dengan cara farmakologi yaitu dengan memberikan tablet $\mathrm{Fe}$ (dosis 1x1) minimal sebanyak 90 tablet selama kehamilan sesuai dengan program pemerintah, untuk ibu hamil dengan anemi ringan diberikan tablet Fe 1x1 tablet sehari, ibu hamil dengan anemi sedang $1 \times 1$ sehari dan untuk ibu hamil dengan anemia berat $2 \times 1$ tablet sehari. Secara non farmakologis adalah dengan menganjurkan makan sayur hijau, makan daging dan telur namun kurang efektif. Kendala lainnya dari konsumsi 90 tablet $\mathrm{Fe}$ yang diberikan adalah konsumsi $\mathrm{Fe}$ pada ibu hamil tidak diminum teratur karena baunya yang amis tidak disukai ibu hamil dan ada ibu hamil yang tidak meminum karena konstipasi.

Hasil studi pendahuluan di wilayah Puskesmas Karangawen II Kabupaten Demak pada bulan Oktober 2019 didapatkan bahwa terdapat 7 ibu hamil dengan anemia ringan, $6 \mathrm{ibu}$ 
hamil dengan anemia sedang dan $2 \mathrm{ibu}$ hamil dengan anemia berat. Beberapa keluhan yang dirasakan yaitu cepat lelah, sering pusing dan nafsu makan menurun. Sebanyak 7 ibu hamil mengatakan untuk mengurangi anemia dengan konsumsi bayam, telur, buah, daging, sayuran hijau, 5 ibu hamil mengatakan hanya minum obat dari puskesmas saja, sedangkan 4 ibu hamil mengatakan makan daging kambing biar darahnya normal. Uraian tersebut menjadi latar belakang untuk melakukan penelitian tentang efektivitas buah kurma dan buah bit terhadap kadar hemoglobin pada ibu hamil trimester II di wilayah puskesmas Karangawen II Kabupaten Demak.

\section{METODE PENELITIAN}

\section{MATERIAL}

Jenis penelitian adalah Quasi Eksperimen dimana peneliti melakukan percobaan terhadap variabel independen untuk mengetahui hubungan sebabakibat. (Sugiyono, 2012)

\section{Rancangan Penelitian}

Desain penelitian ini menggunakan rancangan two group pretest-posttest design dimana dua kelompok subjek diukur sebelum dan setelah perlakuan. (Sugiyono, 2012)

\section{HASIL DAN PEMBAHASAN}

Penelitian dilakukan pada bulan Juli 2020 di wilayah kerja Puskesmas Karangawen II Demak dengan sampel sejumlah $36 \mathrm{ibu}$ hamil dengan anemia sebagai responden, dibagi menjadi 2 kelompok yang masing-masing berjumlah 18 responden. Kelompok A diberikan buah kurma basah sebanyak $3 \times 2$ biji/hari selama 7 hari dan Kelompok B diberikan buah bit sebanyak 3x200 gr/hari selama 7 hari yang sudah diolah peneliti Pengukuran kadar $\mathrm{Hb}$ dikedua kelompok dilakukan pada hari pertama yaitu sebelum diberikan intervensi dan hari ke-8 yaitu sesudah dilakukan intervensi. Pada intervensi yang diberikan masingmasing kelompok, seluruh responden tetap mengkonsumsi tablet $\mathrm{Fe}$ yang didapatkan dari Bidan/Puskesmas.

\section{HASIL}

\section{Pengaruh Buah Kurma Terhadap Kadar Hb Ibu Hamil Trimester II}


Tabel 1.1 Distribusi Buah Kurma Terhadap Kadar Hb Ibu Hamil Trimester II

\begin{tabular}{llllllc}
\hline \multicolumn{1}{c}{ Variabel } & n & Min & Max & Mean & Median & $\begin{array}{c}\text { Std. } \\
\text { Deviastion }\end{array}$ \\
\hline $\begin{array}{l}\text { Kadar Hb ibu } \\
\text { hamil sebelum }\end{array}$ & 18 & 9,0 & 11,0 & 9,961 & 10,000 & 0,6436 \\
pemberian buah \\
kurma
\end{tabular}

Berdasarkan tabel 1.1 dapat berikan buah kurma sebesar 0,6426. dilihat nilai minimum $\mathrm{Hb}$ sebelum Sedangkan nilai minimum $\mathrm{Hb}$ sesudah diberikan buah kurma sebesar 9,0 dan diberikan buah kurma sebesar 10,0 dan maksimum 11,0, nilai mean $\mathrm{Hb}$ sebelum maksimum 12,4, nilai mean 11,139, diberika kurma 9,961, median 10,000 median 10,950 dan nilai standard dan standar deviasi $\mathrm{Hb}$ sebelum di deviasi 0,6997.

Tabel 1.2 Pengaruh Buah Kurma Terhadap Kadar Hb Ibu Hamil Trimester II

\begin{tabular}{lccc}
\hline \multicolumn{1}{c}{ Intervensi } & $\mathrm{n}$ & Mean & $p$-value \\
\hline Sebelum & 18 & 9,961 & $0,000 *$ \\
\hline Sesudah & 18 & 11,139 & \\
\hline Uji T-dependent & & &
\end{tabular}

Kelompok intervensi buah kurma pada Tabel 1.2 menunjukkan $p$-value $=$ $0,000(<0,05)$ artinya ada perbedaan kadar $\mathrm{Hb}$ ibu hamil trimester II sebelum dan sesudah diberikan buah kurma.

\section{Pengaruh Buah Bit Terhadap Kadar Hb Ibu Hamil Trimester II}

Tabel 1.3 Distribusi Buah Bit Terhadap Kadar Hb Ibu Hamil Trimester II

\begin{tabular}{llccccc}
\hline \multicolumn{1}{c}{ Variabel } & n & Min & Max & Mean & Median & $\begin{array}{c}\text { Std. } \\
\text { Deviastion }\end{array}$ \\
\hline $\begin{array}{l}\text { Kadar Hb ibu hamil } \\
\text { sebelum } \\
\text { pemberian buah bit }\end{array}$ & 18 & 9,0 & 11,0 & 10,050 & 10,000 & 0,6355 \\
$\begin{array}{l}\text { Kadar Hb ibu } \\
\text { hamil sesudah } \\
\text { pemberian buah }\end{array}$ & 18 & 9,5 & 11,8 & 10,483 & 10,500 & 0,7318 \\
bit & & & & & \\
\hline
\end{tabular}

Berdasarkan tabel 1.2 dapat dilihat nilai minimum $\mathrm{Hb}$. sebelum diberikan buah bit sebesar 9,0 dan 70 maksimum 11,0, nilai mean 10,050, median 10,000 dan standar sebesar 0,6355 . Sedangkan nilai minimum $\mathrm{Hb}$ 
sesudah diberikan buah bit sebesar 9,5 median 10,500 dan nilai standard dan maksimum 11,8 , nilai mean 10,483 , deviasi 0,7318 .

Tabel 1.4 Pengaruh Buah Bit Terhadap Kadar Hb Ibu Hamil Trimester II

\begin{tabular}{lccc}
\hline \multicolumn{1}{c}{ Inrevensi } & $\mathrm{n}$ & Mean & $p$-value \\
\hline Sebelum & 18 & 10,050 & $0,000^{*}$ \\
\hline *esudah & 18 & 10,483 & \\
*ji T-dependent & & &
\end{tabular}

Kelompok intervensi buah bit kadar $\mathrm{Hb}$ ibu hamil trimester II sebelum pada Tabel 1.4 menunjukkan $p$-value $=\quad$ dan sesudah diberikan buah bit. $0,000(<0,05)$ artinya ada perbedaan

Pengaruh Buah Kurma dan Buah Bit Terhadap Kadar Hb Ibu Hamil Trimester II

Tabel 4.5 Pengaruh Buah Kurma dan Buah Bit Terhadap Kadar Hb Ibu Hamil Trimester II

\begin{tabular}{lccc}
\hline \multicolumn{1}{c}{ Variabel } & $\mathrm{n}$ & Mean & p-value \\
\hline $\begin{array}{l}\text { Peningkatan kadar } \mathrm{Hb} \\
\text { Kelompok A }\end{array}$ & 18 & 1,178 & \\
\hline $\begin{array}{l}\text { Peningkatan kadar } \mathrm{Hb} \\
\text { Kelompok B }\end{array}$ & 18 & 0,433 & $0,000^{*}$ \\
*Uji T-dependent & & & \\
\hline
\end{tabular}

Perlakuan peningkatan kadar $\mathrm{Hb}$ pada Kelompok A dan Kelompok B memiliki $\quad p$-value $=0.000, \quad$ artinya terdapat perbedaan signifikan pada kedua kelompok. Peningkatan kadar $\mathrm{Hb}$ pada Kelompok A lebih besar (1,178 $\mathrm{gr} / \mathrm{dl}$ ) daripada peningkatan kadar $\mathrm{Hb}$ pada Kelompok B $(0,433$ gr/dl) hal ini menunjukkan bahwa buah kurma lebih efektif dibandingkan buah bit terhadap peningkatan kadar $\mathrm{Hb}$ ibu hamil trimester II di wilayah puskesmas Karangawen II Kabupaten Demak.

\section{PEMBAHASAN}

Penurunan kadar hemoglobin selama kehamilan dapat mempengaruhi keshatana janin. Defisiensi Fe terjadi pada kehamilan diakibatkan adanya peningkatan kebutuhan zat besi, pembentukan jaringan baru dan juga kebutuhan janin yang terus bertambah. Untuk mengatasi anemia pada masa kehamilan dapat juga dilakukan dengan cara non farmakologi yaitu cara mengkonsumsi buah kurma dan buah bit. (Oebroto, 2016)

\section{Buah Kurma}

Hasil penelitian pada Kelompok A 
menunjukkan $\quad p$-value $=0,000(<0,05)$ sehingga ada perbedaan signifikan kadar $\mathrm{Hb}$ ibu hamil trimester II sebelum dan sesudah diberikan buah kurma. Pada ibu hamil yang mengkonsumsi buah kurma mengatakan bahwa tidak ada kendala saat mengkonsumsi buah kurma sehingga dalam mengkonsumsi buah kurma ini efektif untuk meningkatkan kadar hemoglobin ibu hamil. (Susilowati, 2017)

Hal ini sejalan dengan penelitian Dahlan (2021) dan Rahmawati (2019) bahwa absorbsi zat besi selama kehamilan berlangsung efisien terhadap terapi ferro sulfat melalui oral. Pemberian tablet Fe disertai konsumsi buah kurma secara rutin dapat memaksimalkan peningkatkan hemoglobin sehingga membantu mencegah anemia.

\section{Buah Bit}

Hasil penelitian pada Kelompok B menunjukkan $p$-value $=0,000(<0,05)$ sehingga ada perbedaan signifikan kadar $\mathrm{Hb}$ ibu hamil trimester II sebelum dan sesudah diberikan buah bit, sehingga dapat disimpulkan bahwa terjadi peningkatan kadar $\mathrm{Hb}$ sesudah diberikan buah bit (posttest). Dukungan dari keluarga untuk mengkonsumsi buah bit setiap pagi, siang dan sore, serta konsumsi tablet Fe (1x1), merupakan faktor keberhasilan peningkatan kadar Hb. Selama proses penelitian tidak ada keluhan pada ibu hamil saat mengkonsumsi buah bit, seperti mual, muntah ataupun respon alergi terhadap buah bit. (Suryandari, 2015) Peningkatan haemoglobin pada ibu hamil setelah mengkonsumsi buah bit ini menunjukkan bahwa dalam mengatasi anemia ibu hamil tidak hanya dapat dilakukan secara farmakologis namun dapat juga digunakan dengan cara non farmakologis dengan memberikan buah bit (Sylvana et al., 2020). Kandungan vitamin $\mathrm{C}$ dalam buah bit lebih besar daripada buah jeruk sehingga mendapat keefektifan penyerapan zat besi dan meningkatkan daya tahan tubuh. (Rokhana, 2018; Setyiyaningsih et al., 2020)

Efektivitas Buah Kurma dan Buah Bit Terhadap Kadar Hemoglobin Pada Ibu Hamil Trimester II Di Wilayah Puskesmas Karangawen II Kabupaten Demak.

Peningkatan kadar Hb pada Kelompok A dan Kelompok B memiliki $p$ value $=0.000$, artinya terdapat perbedaan signifikan pada kedua kelompok.. Buah kurma lebih efektif 
meningkatkan kadar $\mathrm{Hb}$ ibu hamil trimester II dibandingkan buah bit. Konsumsi 90 tablet $\mathrm{Fe}$ secara rutin dapat mencegah anemia selama kehamilan. Selain itu, ibu hamil juga dapat mengkonsumsi berbagai sayur dan buah, salah satunya adalah dengan mengkonsumsi buah kurma (Sephia, 2020). Kandungan nutrisi dalam buah kurma (antioksidan, nutrisi, magneisum, natrium, kalium, vitamin $\mathrm{C}$, dan betaine) berperan penting dalam memproduksi hemoglobin. (Amaris et al., 2021) Konsumsi buah kurma tidak hanya dapat meningkatkan kadar hemoglobin, kurma juga dapat berperan dalam meningkatkan feritin, hematokrit, mentransfer saturasi dan kadar zat besi (Rahmawati et al., 2020). Kurma juga merupakan salah satu sumber antioksidan terbaik, dimana antioksidan yang terkandung berupa karotenoid, fenolik dan tannin. Antioksidan ini berperan dalam pencegahan penyakit diabetes, kanker dan penyakit kardiovaskuler (Utami \& Graharti, 2017).

\section{KESIMPULAN}

1. Kadar $\mathrm{Hb}$ ibu hamil trimester II sebelum diberikan kurma nilai mean 9,961. Setelah diberikan buah kurma nilai mean sebesar 11,139.

2. Kadar $\mathrm{Hb}$ ibu hamil trimester II sebelum diberikan buah bit nilai mean sebesar 10,050. Setelah diberikan buah bit nilai mean sebesar 10,500.

3. Buah kurma lebih efektif dibandingkan buah bit terhadap peningkatan kadar $\mathrm{Hb}$ ibu hamil trimester II di wilayah puskesmas Karangawen II Kabupaten Demak.

\section{UCAPAN TERIMA KASIH}

Ucapan terima kasih kami sampaikan kepada Stikes Karya Husada Semarang dan Puskesmas Karangawen II Kabupaten Demak yang telah memberikan dukungan dalam penelitian ini.

\section{DAFTAR PUSTAKA}

Alfiah, Rahmawati. (2019). Pengaruh Konsumsi Kurma (Phoenix Dactylifera) terhadap Kenaikan Kadar Hemoglobin : A Review.

Amaris, A. F., Rachman, H. S., \& Andriane, Y. (2005). Scoping Review: Pengaruh Pemberian Kurma ( Phoenix dactylifera) 
terhadap Kadar Hemoglobin

pada Pasien Anemia .

Dahlan, F. M., \& Ardhi, Q. (2021).

The Effect Of Fe Tablet And

Date Palm On Improving

Hemoglobin Level Among

Pregnant Women In The

Third Semester. Journal of

Midwifery, $5(1)$,

https://doi.org/10.25077/jom.

\section{$\underline{5.2 .32-38.2020}$}

Kartika, I., \& Rokhana. (2018).

Volume 6 No. 2 (Oktober

2018) (C) The Author(s) 2018

PENGARUH BUAH BIT (.

Jnph, 6(2), 60-66.

Pratami, E. (2016). Evidence

Based dalam Kebidanan:

Kehamilan, persalinan, \& nifas.Jakarta:EGC

Profil Kesehatan Indonesia. 20172018. Profil Kesehatan Indonesia. Jakarta.

Profil Kesehatan Jawa Tengah. 20172018. Profil Kesehatan Jawa Tengah.

Semarang.

Profil Kesehatan Kabupaten Demak. 2017-2018. Profil Kesehatan Kabupaten Demak. Demak.

Rahmawati, D. A., As'ad, S., Wardihan Sinrang, A., \& Husnah, R. (2020). Dates and hemoglobin levels: Literature review. European Journal of Molecular and Clinical Medicine, 7(3), 2364-2370.

Riskesdas. (2018). Laporan Riset Kesehatan Dasar. Jakarta: Badan Penelitian dan Pengembangan Kesehatan Kementrian Kesehatan RI. Kemenkes RI

Sephia, E. D. (2020). THE EFFECT OF GIVING SARI KURMA (Phoenix dactylifera) ON INCREASING

HEMOGLOBIN LEVELS OF PREGNANT WOMEN. Jurnal Medika Hutama, 2(01), 377-381. Retrieved from https://jurnalmedikahutama.co m/index.php/JMH/article/vie $\mathrm{w} / 94$

Setyiyaningsih, S., Widayati, W., \& Kristiningrum, W. (2020). Keefektifan Jus Buah Bit Dan Lemon Dalam Kenaikan Kadar $\mathrm{Hb}$ Pada Ibu Hamil. Jurnal Kebidanan Malahayati, 6(1), 71-76. https://doi.org/10.33024/jkm. $\underline{\mathrm{v} 6 \mathrm{i} 1.2350}$ 
Stephana, Wenda. (2018).

Efektivitas Pemberian Jus

Buah Bit Terhadap Kadar

Hemoglobin Ibu Hamil

Dengan Anemia. Universitas

Riau.

Sugiyono. (2012). Metodologi Penelitian Kuantitatif Kualitatif dan $R \& D$.

Bandung: ALABETA.

Suryandari. (2015). Perbandingan

Kenaikan Kadar Hb Pada Ibu

Hamil Yang Diberi Fe

Dengan Fe Dan Buah Bit Di

Wilayah Kerja Puskesmas

Purwokerto Selatan.

Susilowati. (2017). Pengaruh

Pemberian Buah Kurma Pada

Ibu Hamil Tm Iii Dengan

Anemia Terhadap Kadar

Hemoglobin di BPM Tri

Rahayu Setyaningsih Cangkringan Sleman

Yogyakarta

Sylvana, F., Harahap, D., \& Liesmayani, E. E. (2020). Buah Bit Terhadap Peningkatan Kadar Hemoglobin pada Ibu Hamil Trimester III. Healthcare: Jurnal Kesehatan, 1-7.

Utami, N., \& Graharti, R. (2017). Kurma (Phoenix dactylifera) dalam Terapi Anemia Defisiensi Besi. Jurnal Kedokteran Unila, Vol.1 No.3 WHO. (2015). Worldwide prevalence of anemia 2013-2015.WHO global data base on Anaemia Geneva, World Health Organization, 2015. http://www.who.int/vmnis/dat abase/anae mia/anaemia_data_status_t3/e $\mathrm{n}$ 